\title{
Reading Rain, Reading River: An Interpretative Discussion on Rajbanshi Folk Ritual
}

\section{Pragya Sen Gupta \\ Sriparna Das}

\begin{abstract}
$\underline{\text { Abstract }}$
This paper aims at reading the folk rituals concerning rain and river among the Rajbanshi community of North Bengal. The different meanings associated with the ingredients of the rituals and the ritual symbols changed with the passage of time and space structure. However, case studies show that man-nature and super-nature are closely connected and this connection can be observed by reading and interpreting the ritual symbols. The extinction and presence of rituals also hint at how the people practicing them have changed according to their demands and necessities.
\end{abstract}

Keywords: Hudum Deo, Mecheni Khela, Rajbanshi

\section{Discussion:}

This paper is focussed on reading two specific folk rituals of Rajbanshis of North Bengal: Hudum Deo and Mecheni. In terms of discussing folk rituals, it will examine the folk tale, ritual practices and the songs associated with each of them. The attempt here is to identify the symbolic specificities as well as the multiple meanings associated with each narrative.

On this pretext, we expand our readings to Turner's Forest of Symbols and though Turner distinguishes the meanings of a symbol 
in three levels: exegetical, operational and positional, we will discuss only the first two levels of meaning. On an exegetic level, when we look into the ritual symbols, we have our information mostly from secondary sources, i.e the literature available in printed form. Because the field study we have done so far explains the slow disappearance of the rituals. To begin with, we will first discuss the practice of worshipping Hudum Deo, where women pray in nude for the annual rain on a new moon night, is a symbol of pleasing the rain god for a good harvest ${ }^{1}$.

Now, as we derive the exegetic meanings of this ritual, it also helps us to understand the multiple voices of the symbols found in the ritual. For example, in this ritual the symbol of nudity refers to multiple meanings. First, it is an act of pleasing God. Secondly, it is a mark of barren land that needs to be blessed for more production. Here nudity becomes the dominant symbol which allows us to observe the economic representation of their community where rain or water is an absolute necessity for their sustenance. The recessive symbol here would be that of the male members which again portrays the gender role played within the community. The cry for rain is probably also an indication of more powerful fertilization since the community's population had also suffered due to migration and foreign invaders. Hudum Deo thus becomes the symbol of invisible power which will protect them from diseases and natural catastrophes.Here in this paper we can observe how the lack of water has resulted in composition of their folk songs.

Deoya Jhori Aayre

Dakiya Dakiya

Ek Chilki Jhori Deo

Jang Gao Dhuiya 
Translation: God showers on us with a thunder. Splash little water on us and return after taking a bath.

\section{Hudum Deo re Hudum Deo \\ Hagi Acchi Paanideo \\ Hamar Dyashotnai Paani \\ Hagatikaay Bara Baani.}

Translation: Lord Hudum! O Lord Hudum! I have defecated, please give water. In our country there is no water. So we farm without cleaning after defecation.

The above songs speak about two concepts: fear and pollution. The first song invokes the fear of scarcity of water to that extent the God himself is being asked to take a bath. This implies that the image of God in their mind is no less than a human body which also needs to be kept clean. In the second song, fear is of a drought implying scarcity of water and non-yielding sufficient food-crops. Pollution is implied in the second two lines of the song which translates their economic and societal condition and the anxiety of remaining as a polluted group. This needs to be read in the context of how their culture has been visualised by the mainstream communities over the years.

As we have already read that Hudum's idol is a temporary one and it is not designed in the shape of a human being,

Aaye re Deoya Gijji

Dhan Chal Jauk Bhiji.

Aaye re Deoya Shosheya

Maang Niya Thhak Bhyashreya.

Aaye re Deoya Dakiya

DhaanChauljauk Bhashia.

Aaye re Deoyadakiya

Doichiradengmakhiya 
Translation: O God! Come with thunder. Let the paddy and rice get wet. Come God, with the sound of storm. The womb is widened for you. Come God, with roar. Let the paddy and rice float away. Come God, with a call. Will mix curd and flaked rice and serve it.

There is a shift in the tone of this song too. In the first line, when God is summoned, it is just for cultivation. If the paddy field gets drenched, then the crop production will be abundant. The second line where female reproductive organ is mentioned about, it implies that the population should also flourish with the food crops. So there are sufficient mouths to be fed with the production. This is a kind of maintaining balance. But then the tone shifts where an anxiety is covertly expressed when the speaker says let the rice and paddy float away. This is an implication of excess rain which is disastrous for both crops and people. In the final line, there is a mention of flaked rice which is considered to be a secondary food for rural population and mostly used when the crop production is minimal. A quality of flaked rice is that it can fill the hunger even if the amount is less. So Hudum is also offered flaked rice when there is a shortage.

\section{Song 4:}

Hura Hudumer Biyao Hoy

Sitar Sendur Daane Paay

Joy Joy Aaji Hudumer Biyao Hoy

Kaaner Sona Daane Paay

Joy Joy Aaaji HudumerBiyao Hoy

Huda Hudumir Biyao Hoy

Poroner Shari Daane Paay. 
Translation: Hura and Hudum get married, and they get sindur (vermillion powder) as gift. Bless Bless, today is Hudum's marriage and he gets gold for ears as a gift. Hura and Hudum get married and they get Sari as gift.

\section{Song 5:}

Aami Kochur Lotar Maton Helibo Na

Olpo Boyosher Hudum Deo

Aayeaaye re Kaala Megh

AAye Parbot Dhaya

Translation: I'll not wave like creeping plants, O my young Hudum Deo. Come O dark clouds, chasing the mountains.

The fourth and fifth songs are symbolising the association of the marital aspects. In the fourth song, the lines to some extent indicate to what gifts are given on Rajbanshi wedding, while in the fifth song the invocation Hudum is more like a lover and not a God. The song is composed with an idea of a young, energetic God who will chase the women like a passionate lover. Thus, the need of a body merges with the sacred, and what we find is that the supernature is invoked through the natural objects to fulfil the needs of people.

On an operational level, our study is stretched to observe the ritual of Mecheni in Jalpaiguri district of West Bengal. Mecheni Puja is the other name of Tistaburi Puja which is performed on the month of Baishakh. It is performed along with Mecheni Khela which involves collecting rice, paddy and vegetables from the village households in that month. The devotee is usually a woman who along with some other women goes to every Rajbangshi house in the village, sings songs, dances and collects the ingredients. The Mecheni khela is performed throughout the month of Baishakh. 
They carry an umbrella with them which is decorated with flowers and in the handle of it a small piece of cloth containing rice is tied. The umbrella is their symbol of deity which they address as Tistaburi or the river Tista. The symbol of umbrella can also be read as a shelter to the people. Before the umbrella is taken out of the devotee's house, it is worshipped along with the household deities. The devotee holds the umbrella in her hand and one of the members in Mecheni group holds a sacred bamboo stick which they symbolise as Shiva. The group starts singing the Mecheni songs from the devotee's house itself and continues to perform even when they are walking towards the houses of other villagers. Before entering each house they make Uludhwani, after which they enter and inform the residents that they have come for Mecheni Khela. The women folk of each house bring a wooden stool and keep it in front of their household temples. The devotee places the umbrella there to cover the stool. The married women in each house bring some mustard oil, vermillion powder and a plate or a winnowing tray full of paddy or rice and vegetables grown in their crop-fields. The devotee makes a mixture of oil and vermillion and puts three red marks on the umbrella and the stool. She collects the rice and other crops in her bag and leaves a few grains of rice from the cloth attached to the umbrella in the plate as prasad. During this entire ritual practice others sing songs and dance around the umbrella. The stool becomes a sacred space as it is recognised then as a place where Tistaburi has settled. If there is any diseased person in the household, he/she is advised to sit there after the ritual is over as it is believed that the blessed seat of Tistaburi will cure the diseases. Once the collection is over for a day, the Mecheni group assembles in an open space or field where they make a circle and sing the Bhong/ Bish songs or vulgar songs. Like this the ritual is performed for a month until the collection from each household in the village is over. Finally, on the 
last day of Baishakh, Mecheni Puja is performed. On that day the devotee takes bath in the morning, worships the household deities and the sacred umbrella and takes it to the Jalpesh temple. A local priest or Adhikari assists in worshipping the deities in their house. The other women in the Mecheni group also join her and they perform the Mecheni songs and dances while they walk to the temple. In the temple, first they enter the temple building with the umbrella, worship Lord Shiva and return to the temple ground where other groups have also assembled. They make a dongaa, a small alter shaped structure, with plantain stems and mark it with tel-sindur. They place a bunch of bananas, a pair of eggs, flowers and sweets on that dongaa and keep it under the umbrella. Another series of songs and dances are performed. They also light some lamps and incense sticks to pray. Finally the devotee lifts the donga on her head and carries it to the temple pond/lake. The other women also accompany her, and one of them holds the umbrella. The devotee prays to the Sun God and immerses the donga in water and takes a dip. The flowers and rice bag on the umbrella are also immersed in water. The umbrella is washed. Finally, they return to the ground where the entire community sits in a circle and have their meal.

The practice of Hudum Deo has become extinct among the Rajbanshis, while Mecheni Khela is still surviving. The reasons for such changes are space and time. The space for practicing Hudum Deo has become limited and with the arrival of modernization, nudity cannot be exercised in public. On the contrary, Mecheni can be accommodated with time and space since it offers no such secrecy. While Hudum Deo was more primitive forms of ritual, Mecheni to a large extent has been made a part of mainstream culture. Even though Mecheni Khela is performed in the village households, the final emersion takes place in the temple premises. 


\section{Notes:}

1. Biswas, Ratan. 'RajbanshiLokachar O HudumDeo': This ritual is usually performed in the onset of monsoon when in a dark night or a new moon night few married Rajbangshi women gather in a distant farm land. The participants undress themselves and begin the performances related to the ritual. First they make an idol Hudum with clay or cowdung and then chant the mantras to perform the worshipping. These chants are composed in the Rajbangshi language. Since no men are allowed in the venue of ritual, an experienced woman performs the puja. The god is offered a naibidya made of banana, milk, sugar etc. After the puja everyone prostrates in fornt of the idol and prays. Then a couple of women sit on their knees and a plough is tied on their shoulder. They pull the plough like bulls and on the ploughed field few seeds are sowed and a few women enact the performance of planting small plants. Following that they return their village together, and the moment they enter a household, the men folk of that house leave or hide themselves. Likewise, each of them returns to their own house and the performative groups take their clothes and return their home.

2. Tista is a river in north Bengal. The name Tistaburi refers to the river Goddess.

3. The first month in Bengali calendar.

4. It's a sound uttered by women on festive occasions

5. Bish can be literally translated as poison. The Bish songs refer to those which cannot be sung or heard in public because of their contents which are mostly vulgar. 
6. Tel-sindur can be literally translated as oil and vermillion powder. A mixture of mustard oil and vermillion powder is made by the devotee and it is used to mark any object as sacred.

\section{References:}

Barma, D. (2012). Rajbangshi BhasharItihas. Kolkata, Sopan: Kolkata.

Bhakat, D. N. (2006). Naranarayan-Chilarai. Dhuburi: Centre for Ethnic Studies and Research.

Bhakat, D. N. (2013). Rajbansi Loka Sahitya. Dhuburi: Centre for Ethnic Studies and Research.

Gennep, Arnold V. (1960). The Rites of Passage. Chicago, Chicago: University of Chicago Press.

Ghosh, Jagannath, (2003). Bihan Ekti Samudro Pakhi. Loksanskriti Sankhya, Rarbango o Uttarbango (Dwitiyo Parbo), 6(1), Kolkata.

Turner, Victor. (1967). The Forest of Symbols: Aspects of Ndembu Ritual. Ithaca and London: Cornell University Press. 